\title{
TABEL VOLUME BATANG DI BAWAH PANGKAL TAJUK POHON KERUING (Dipterocarpus acutangulus) DI LABANAN BERAU KALIMANTAN TIMUR
}

(Clearbole Volume Table of Keruing (Dipterocarpus acutangulus) in Labanan Berau, East Kalimantan)

Oleh/By:

Abdurachman

Balai Besar Penelitian Dipterokarpa

\begin{abstract}
In all system of forest managements, stocktaking activity constitutes important thing to know the potential of stands. One of activities in forest stocktaking is measurement for stand mass estimation. The result is table of volume where if done by field tree measurements require time and there are many cost. These local clearbole volume tables were constructed with the aim to the improvement of stand volume estimation of Keruing (Dipterocarpus acutangulus) in Labanan, Berau Distric, East Kalimantan. It was based on 77 selected sample trees taken from the field, which latter was analyzed by using the statistical formulas. The result of analysis showed that the regression equations used for volume were $\log V=-3.7914+2.4022 \log d$ with standard error of 0.1179 , Correlation coefficient $(r)$ 0.9815 , agregatif deviation (SA) $-1.86 \%$ and average deviation (SR) $3.21 \%$.
\end{abstract}

Key Words : Diameter, Volume table, Keruing (Dipterocarpus acutangulus).

\begin{abstract}
ABSTRAK
Dalam semua sistem pengelolaan hutan, kegiatan inventarisasi merupakan hal yang penting untuk mengetahui potensi tegakan. Salah satu kegiatan dalam inventarisasi hutan adalah pengukuran untuk penaksiran massa tegakan. Hasil berupa tabel isi dimana jika dilakukan pengukuran pohon secara langsung memerlukan waktu dan biaya yang banyak. Tabel volume batang dibawah pangkal tajuk dibuat dengan tujuan untuk meningkatkan taksiran dari volume Dipterocarpus acutangulus di Labanan Berau, Kalimantan Timur. Sebanyak 77 sampel pohon model diambil dari areal penelitian. Analisis data menggunakan rumus-rumus statistik. Hasil analisis menunjukkan bahwa persamaan yang digunakan adalah $\log \mathrm{V}=-3,7914+2,4022 \log \mathrm{d}$ dengan kesalahan baku 0,1179, koefisien korelasi $(r)$ 0,9815, simpangan agregatif $-1,86 \%$ dan simpangan rataan (SR) $3,21 \%$.
\end{abstract}

Kata Kunci : Diameter, Tabel volume, Dipterocarpus acutangulus. 


\section{PENDAHULUAN}

Pada kegiatan pengelolaan hutan diperlukan suatu perencanaan hutan yang mantap, cermat dan terkendali sehingga diperoleh hasil yang maksimal dan lestari. Sehubungan dengan hal itu inventarisasi hutan merupakan bagian dari kegiatan perencanaan hutan yang paling penting. Hal ini karena data hasil inventarisasi tersebut dipakai sebagai dasar utama di dalam pemanfaatan hutan yang dilakukan.

Salah satu kegiatan dalam inventarisasi hutan adalah pengukuran untuk penaksiran massa tegakan yang berupa tabel isi dimana jika dilakukan pengukuran pohon secara langsung memerlukan waktu serta biaya yang banyak. Dalam kegiatan inventarisasi hutan untuk penaksiran massa tegakan, diperlukan perangkat kuantitatif berupa model pendugaan volume atau tabel volume pohon yang valid. Pengukuran volume tegakan dapat dilakukan secara langsung pada pohon, tetapi memerlukan waktu, tenaga dan biaya yang besar. Dari aspek lain, penyusunan perencanaan hutan dan pengaturan hasil juga memerlukan tersedianya tabel volume lokal (tarif) yang berlaku pada daerah pengelolaan hutan tersebut.

Tujuan dari penyusuanan tabel ini adalah untuk meningkatkan ketelitian dan keseksamaan dari hasil inventarisasi massa tegakan dari jenis pohon yang bersangkutan. Hasil penelitian ini diharapkan dapat dipergunakan dalam pelaksanaan timber cruising di lapangan bagi keperluan penyusunan rencana-rencana pengusahaan hutan setempat.

\section{RISALAH JENIS}

Pohon keruing (Dipterocarpus acutangulus) adalah salah satu jenis dari famili Dipterocarpaceae. Secara geografis penyebaran spesies berada di Peninsular Malaysia dan Borneo. Secara ekologi tumbuhan daerah tanah berpasir dan lempung berpasir pada habitat hutan di dataran rendah atau bukit-bukit dan pegunungan sampai ketinggian $1.000 \mathrm{~m}$. Pohon Dipterocarpus acutangulus memiliki kayu keras, bisa mencapai ketinggian melebihi 60 meter dengan banir yang rendah dan diameter mencapai $>130 \mathrm{~cm}$ (Soerianegara dan Lemmens, 1994).

Sebagaimana jenis dari keruing lainnya kegunaan kayu dari jenis ini adalah untuk konstruksi medium dan berat. Kontruksi bangunan, lantai, karoseri, bangunan pelabuhan, perkapalan dan bantalan kereta api. Selain itu digunakan juga untuk pembuatan veneer dan kayu lapis (Soerianegara dan Lemmens, 1994; Martawijaya dkk, 1981).

\section{KEADAAN UMUM LOKASI PENELITIAN}

Secara geografis, lokasi penelitian terletak pada posisi $1^{\circ} 45^{\prime}-2^{\circ} 10^{\prime} \mathrm{LU}$ dan $116^{\circ} 57^{\prime}-117^{\circ} 27^{\prime} \mathrm{BT}$. Berdasarkan data iklim Stasiun Bandara Kalimarau Tanjung Redeb Kabupaten Berau, rata-rata curah hujan tahunan $2.404 \mathrm{~mm}$. Bulan kering terjadi pada bulan Agustus dan September, sedangkan bulan 
basah terjadi pada bulan Desember dan Januari. Tipe iklim menurut Schmidt dan Ferguson (1951) lokasi penelitian memiliki nilai $\mathrm{Q}=16,17 \%$ tergolong tipe iklim $\mathrm{B}(\mathrm{Q}=14,3-33,3 \%)$, sementara di bagian selatan memiliki nilai $\mathrm{Q}=4,20 \%$ termasuk tipe iklim A dengan curah hujan rata-rata 2.500$3.000 \mathrm{~mm}$ per tahun. Suhu udara maksimum $35^{\circ} \mathrm{C}$ terjadi pada bulan September dan Nopember dan terendah $33^{\circ} \mathrm{C}$ pada bulan Januari. Suhu udara minimum tertinggi $22^{\circ} \mathrm{C}$ terjadi pada bulan Mei dan Juni dan minimum terendah $21^{\circ} \mathrm{C}$ terjadi pada bulan Februari dan Agustus. Jenis tanah didominasi oleh Podsolik Haplik (Typic Paleudults) dan Podsolik cromik (Typic Hapluduts). Tanah-tanah tersebut memiliki tekstur lempung, lempung liat berpasir hingga lempung berliat dan liat berwarna coklat kekuning-kuningan dengan struktur gumpal tak bersudut hingga bersudut. Drainase sedang hingga baik dan kedalaman efektif adalah $>100 \mathrm{~cm}$. Topografi daerah ini memiliki tingkat kelerengan ringan atau datar. Kondisi tersebut meliputi 36\% dari luas areal, sedangkan luas kawasan lainnya dicirikan dengan kondisi kelerengan curam yang meliputi $25 \%$ dari luas areal. Kelerengan lebih dari 40\% meliputi 5,58\% dari luas wilayah pengelolaan hutan Labanan yang dikatagorikan sangat curam (Anonim, 1999).

Menurut Sist dan Saridan (1998), pada areal ini terdapat sebanyak 76 spesies Dipterocarpaceae yang terdiri dari Anisoptera dua jenis, Cotylelobium satu jenis, Dipterocarpus 15 jenis, Dryobalanops satu jenis, Hopea tujuh jenis, Parashorea dua jenis, Shorea 38 jenis, Vatica 10 jenis. Suku lainnya Euphorbiaceae, antara lain: Elateriospermum tapos, Chaetocarpus castanocarpus, Drypetes kikir, Koilodepas brevipes dan Baccaurea spp. Dari suku Sapotaceae diantaranya adalah Madhuca spp. dan Palaquium spp. ; Myristicaceae di antaranya Knema spp. dan Horsfieldia spp. ; Burseraceae antara lain Dacryodes spp. dan Canarium spp. ; Ebenaceae yaitu Diospyros spp. ; Leguminosae seperti Koompassia spp. dan Sindora spp.; Anacardiaceae seperti Gluta spp dan Smecarpus spp; Annonaceae yaitu Polyalthia spp., Goniothalamus spp. dan Sageraea sp. ; Lauraceae antara lain Actinodaphne spp. dan Beilschmiedia spp. dan Sterculiaceae yaitu Scaphium spp. dan Heriteira spp.

\section{METODE PENELITIAN}

\section{A. Pengukuran pohon model}

Pohon model yang dikumpulkan adalah pohon berdiri dengan jumlah 77 pohon, dipilih secara sengaja untuk mendapatkan pohon model yang mewakili setiap kelas diameter. Diameter pohon diukur pada ketinggian 1,3 m dari permukaan tanah atau $20 \mathrm{~cm}$ diatas puncak banir. Tinggi pangkal tajuk dan diameter per seksi diukur dengan menggunakan alat Spiegeelascl rope. Setiap pohon contoh dibagi menjadi beberapa seksi tergantung tingginya, adapun panjang setiap seksi adalah $2 \mathrm{~m}$, kecuali pada awal seksi $1 \mathrm{~m}$ dan ujung dibawah pangkal tajuk $<2 \mathrm{~m}$.

\section{B. Pengolahan data}

Pengolahan data hasil pengukuran pohon model di lapangan meliputi : 


\section{Pengukuran diameter}

Diameter perseksi di ukur dengan rumus : $\mathrm{D}=\mathrm{a} \times \mathrm{b} \times 2$

Dimana:

$\mathrm{D}=$ Diameter per seksi

$\mathrm{a}=$ Jarak datar

$\mathrm{b}=$ Jumlah relatif unit yang masuk pada Spiegel relascope

2. Volume seksi perpohon

Dasar perhitungan volume perseksi yang dipakai adalah berdasarkan rumus Smalian (Chapman dan Meyer, 1949), yaitu :

$\mathrm{V}_{\mathrm{i}}=\left[\left(\mathrm{G}_{\mathrm{pi}}+\mathrm{G}_{\mathrm{ui}}\right) / 2\right] \times \mathrm{P}_{\mathrm{i}}$

Dimana:

$\mathrm{V}_{\mathrm{i}} \quad=$ Volume seksi ke $-\mathrm{i}\left(\mathrm{m}^{3}\right)$

$\mathrm{G}_{\mathrm{pi}} \quad=$ Luas bidang dasar pangkal pada seksi - $\mathrm{i}$

$\mathrm{G}_{\mathrm{ui}} \quad=$ Luas bidang dasar ukung pada seksi - $\mathrm{i}$

$\mathrm{P}_{\mathrm{i}} \quad$ = Panjang seksi - $\mathrm{i}$

3. Volume pohon model

Volume pohon model diperoleh dari penjumlahan volume dari seksi-seksi yang membentuknya yang dihitung dengan cara :

$\mathrm{V}_{\text {pohon }}=\Sigma \mathrm{V}_{\mathrm{i}} \quad(\mathrm{i}=1,2,3 \ldots \mathrm{n})$

Dimana:

$\mathrm{V}_{\text {pohon }}=$ Volume pohon $\left(\mathrm{m}^{3}\right)$

$\mathrm{V}_{\mathrm{i}} \quad=$ Volume seksi ke $-\mathrm{i}$

$\mathrm{n} \quad=$ Banyaknya seksi

\section{C . Penyusunan Model Pendugaan Volume Pohon}

Volume pohon diperoleh dari penjumlahan volume per seksi pada pohon yang bersangkutan. Volume pohon kemudian dihubungkan dengan peubah bebas untuk mendapatkan persamaan volume. Metode pendugaan volume lokal ini berdasarkan satu peubah saja yaitu diameter. Loetsch dan Haller (1973) menyatakan bahwa tabel volume lokal dibatasi oleh pemakaiannya yaitu terbatas pada jenis atau kelompok dan kondisi tapak yang sama. Jumlah pohon untuk penyusunan tabel volume ini berkisar antara 25 - 30 pohon model dengan memperhatikan sebaran diameter (Chapman dan Meyer, 1949). Dalam penelitian ini bentuk persamaan regresi yang disusun disajikan pada Tabel 1 berikut ini. 
Tabel (Table) 1. Persamaan regresi menduga volume pohon berdasarkan diameter setinggi dada.

(Regression equation to predict wood volume based on diameter at breast height)

\begin{tabular}{|c|l|l|l|}
\hline No & $\begin{array}{c}\text { Peubah Bebas/ } \\
\text { Variable of freedom }\end{array}$ & Dikembangkan Oleh/Developed By & Model rumus/formula model \\
\hline 1 & Diameter (d) & Kopazky - Gehrhardt & $\mathrm{V}=\mathrm{b}_{0}+\mathrm{b}_{1} \mathrm{~d}^{2}$ \\
2 & Diameter (d) & Hohendl - Krenn & $\mathrm{V}=\mathrm{b}_{0}+\mathrm{b}_{1} \mathrm{~d}+\mathrm{b}_{2} \mathrm{~d}^{2}$ \\
3 & Diameter (d) & Husch & Log V $=\mathrm{b}_{0}+\mathrm{b}_{1} \operatorname{logd}$ \\
4 & Diameter (d) & Brenac & Log V $=\mathrm{b}_{0}+\mathrm{b}_{1} \operatorname{logd}+\mathrm{b}_{2}(1 / \mathrm{d})$ \\
5 & Diameter (d) & Bustomi et al. (1998) & $\mathrm{V}=\mathrm{a}+\mathrm{b} \log \mathrm{d}$ \\
\hline
\end{tabular}

Sumber : Nomor 1 s/d 4 dari Loetsch dan Haller (1973)

\section{Validasi Persamaan Terpilih}

Loetsch dan Haller (1973) menyatakan bahwa tabel volume lokal dibatasi oleh pemakaiannya yaitu terbatas pada jenis atau kelompok dan kondisi tapak yang sama. Sedangkan menurut Spurr (1951) dan Husch (1963) bahwa model pendugaan volume pohon yang baik adalah persamaan yang mempunyai nilai simpangan agregatif kurang dari 1\% dan simpangan rataan kurang dari 10\%.

\section{HASIL DAN PEMBAHASAN}

\section{A. Pengukuran Pohon Model}

Pengukuran pohon model dilakukan dengan mengambil sebaran diameter yang secara purposif dipilih untuk memenuhi dari kelas diameter yang ada di lapangan. Pohon model yang telah diambil sebanyak 77 pohon dengan diameter berkisar antara 10 - >80 cm yang menyebar pada setiap kelas diameter. Sebaran diameter dari setiap jenis yang diambil sebagai pohon model dari setiap jenis dalam kelas diameter dengan interval 10 secara grafis dapat digambarkan sebagai berikut.

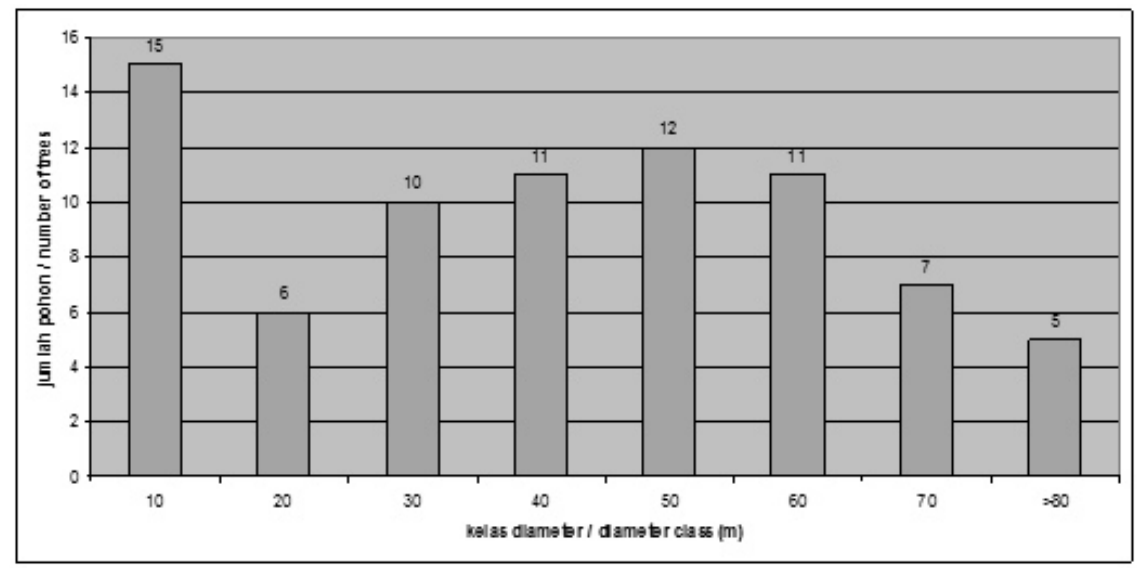

Gambar (Figure) 1. Sebaran kelas diameter pohon model Dipterocarpus acutangulus (Distribution of diameter class of Dipterocarpus acutangulus sample trees). 


\section{B. Hubungan Diameter dan Tinggi}

Untuk pembuatan model pendugaan volume berdasarkan variabel-variabel yang dibuat perlu dilakukan analisis hubungan antara diameter dan tinggi. Hal ini dimaksudkan agar dapat ditentukan dalam pembuatan persamaannya fungsi yang dipakai menggunakan diameter saja atau keduanya, bila dalam analisis memilki hubungan yang erat maka cukup dipakai diameter saja. Rekapitulasi hasil perhitungan dengan mencobakan hubungan diameter-tinggi dapat dilihat pada Tabel 2.

Tabel (Table) 2. Persamaan regresi hubungan antara diameter dan tinggi bebas cabang untuk jenis

Dipterocarpus acutangulus (Regression equation of relationship between diameter dan heigh of crown base of Dipterocarpus acutangulus)

\begin{tabular}{|c|c|c|c|c|c|}
\hline No & Jenis/species & Persamaan/equation & $\begin{array}{c}\text { Koef. } \\
\text { Korelasi/koef. } \\
\text { correlation }\end{array}$ & $\begin{array}{c}\text { Koef. } \\
\text { Determinasi/koef. } \\
\text { determination }\end{array}$ & $\begin{array}{c}\text { Kesalahan } \\
\text { baku/Standard } \\
\text { Error }\end{array}$ \\
\hline 1. & Dipterocarpus acutangulus & $\mathrm{T}=11.473+0.2629 \mathrm{D}-0.001 \mathrm{D}^{2}$ & 0.7773 & 0.6042 & 3.1407 \\
\hline
\end{tabular}

Dari hasil analisis tersebut terlihat nilai $r$ yang besar, selanjutnya nilai ini dapat diuji dengan melihat besarnya $r$-tabel (pada taraf signifikansi 0,01 memiliki nilai 0,296) dan ternyata memiliki nilai yang lebih besar sehingga diantara keduanya peubah tersebut terdapat hubungan yang signifikan. Dengan demikian, penyusuanan persamaan volume dapat dengan hanya menggunakan satu variabel saja yaitu diameter (Tarif). Kurva hubungan regresi diameter dan tinggi ini dapat dilihat pada Gambar 2 berikut ini.

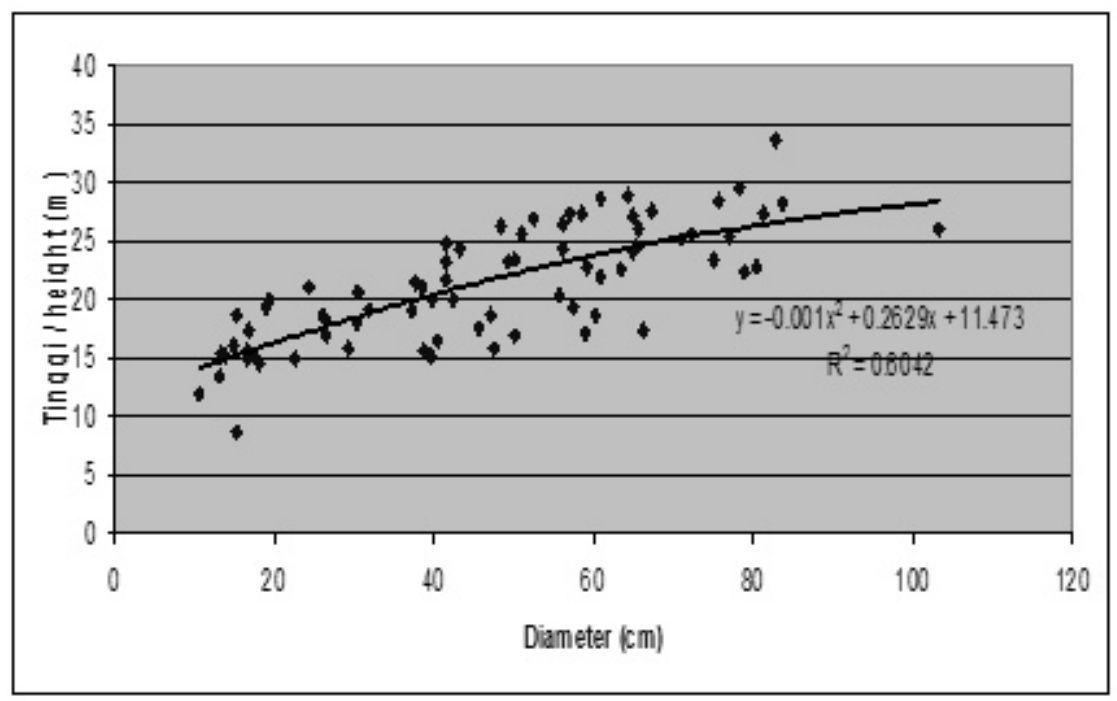

Gambar (Figure) 2. Kurva hubungan diameter dan tinggi pohon model (Curve of relationship between diameter and high of crown base of sample trees) 
Selanjutnya dilakukan analisis kurva tinggi. Hasil analisis kurva tinggi untuk jenis ini ditunjukkan dalam tabel Analisis Varians (Anova) berikut.

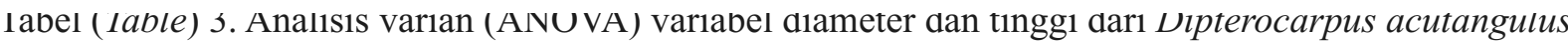

(Analysis of Varians of diameter and height of Dipterocarpus acutangulus).

\begin{tabular}{|l|r|r|r|r|r|}
\hline $\begin{array}{l}\text { Sumber Keragaman } \\
\text { /source of variation }\end{array}$ & $\begin{array}{c}\text { Derajat bebas/ degree } \\
\text { of freedom }\end{array}$ & $\begin{array}{l}\text { Jumlah kuadrat / } \\
\text { Sum of Square }\end{array}$ & $\begin{array}{l}\text { Rataan kuadrat/ } \\
\text { Mean of square }\end{array}$ & Fhit/Fval & $F_{\text {tab99\% }}$ \\
\hline $\begin{array}{l}\text { Regresi/ } \\
\text { Regression }\end{array}$ & 2 & 1114.32 & 557.16 & 56.48 & 3.12 \\
\hline $\begin{array}{l}\text { Sisa/ } \\
\text { Residual }\end{array}$ & 74 & 729.97 & 9.86 & & \\
\hline Jumlah/Total & 76 & 1844.29 & & & \\
\hline
\end{tabular}

Dari analisis pada Tabel 3 terlihat bahwa persamaan yang dicobakan terlihat memiliki sebaran data yang signifikan dimana hal ini ditunjukkan dengan besarnya nilai F-hitung yang lebih besar dari F-tabel.

\section{Penyusunan Persamaan Volume}

Hasil pengujian dari beberapa persamaan regresi yang dihasilkan untuk penyusunan tabel volume lokal (tarif) dari setiap jenis disajikan pada tabel berikut ini.

Tabel (Table) 4. Hasil pengolahan beberapa persamaan regresi yang diuji untuk jenis Dipterocarpus acutangulus (The result preparation test several Regression equation of Dipterocarpus acutangulus)

\begin{tabular}{|c|c|c|c|c|}
\hline No & Persamaan/equations & $\begin{array}{c}\text { Koef. } \\
\text { Korelasi/koef. } \\
\text { correlation }\end{array}$ & $\begin{array}{c}\text { Koef. } \\
\text { determinasi/koef. } \\
\text { determination }\end{array}$ & $\begin{array}{c}\text { Kesalahan } \\
\text { baku/Standard } \\
\text { Error }\end{array}$ \\
\hline 1 & $\mathrm{~V}=-0.2723+0.0012 \mathrm{~d}^{2}$ & 0.9634 & 0.9282 & 0.7538 \\
\hline 2 & $\mathrm{~V}=-0.2017-0.0035 \mathrm{~d}+0.0012 \mathrm{~d}^{2}$ & 0.9635 & 0.9283 & 0.7587 \\
\hline 3 & $\log \mathrm{V}=3.6751+2.4022 \log \mathrm{d}$ & 0.9815 & 0.9633 & 0.1179 \\
\hline 4 & $\log \mathrm{V}=3.5989+2.3639 \log \mathrm{d}-0.4983(1 / \mathrm{d})$ & 0.9814 & 0.9633 & 0.1187 \\
\hline 5 & $\mathrm{~V}=-12.0621+0.93741 \log \mathrm{d}$ & 0.8384 & 0.7029 & 1.5335 \\
\hline
\end{tabular}

$\mathrm{R}^{2}=$ koefisien determinasi, $\mathrm{Se}=$ Galat baku

Dari hasil analisis tersebut terlihat nilai $r$ yang besar, selanjutnya nilai ini dapat diuji dengan melihat besarnya $r$-tabel (pada taraf signifikansi 0,01 memiliki nilai 0,296) dan ternyata memiliki nilai yang lebih besar sehingga diantara keduanya peubah tersebut terdapat hubungan yang signifikan.

Hasil analisis variasi untuk persamaan 3 jenis ini ditunjukkan dalam tabel Analisis Varians (Anova). Dari analisis pada Tabel 5 terlihat bahwa persamaan yang dicobakan terlihat memiliki sebaran data yang signifikan dimana hal ini ditunjukkan dengan besarnya nilai F-hitung yang lebih besar dari F-tabel.

Berdasarkan nilai koefisien determinasi dan nilai standar eror serta nilai F-hitung dari persamaan yang terbentuk hasil analisis regresi yang dilakukan, maka persamaan regresi yang terpilih untuk jenis ini adalah Persamaan Regresi no 3. 
Tabel (Table) 5. Analisis varian (ANOVA) variabel volume dan diameter dari Dipterocarpus acutangulus (Analysis of Varians of Volume and diameter of Dipterocarpus acutangulus)

\begin{tabular}{|l|c|c|c|c|c|}
\hline $\begin{array}{l}\text { Sumber Keragaman } \\
\text { /source of variation }\end{array}$ & $\begin{array}{c}\text { Derajat bebas/degree } \\
\text { of freedom }\end{array}$ & $\begin{array}{c}\text { Jumlah kuadrat/ } \\
\text { Sum of Square }\end{array}$ & $\begin{array}{c}\text { Rataan kuadrat/ } \\
\text { Mean of square }\end{array}$ & $F_{\text {hit/ }} / F_{\text {val }}$ & $F_{\text {tab } 99 \%}$ \\
\hline $\begin{array}{l}\text { Regresi/ } \\
\text { Regression }\end{array}$ & 1 & 27.41 & 27.41 & 1969.83 & 3.12 \\
\hline $\begin{array}{l}\text { Sisa/ } \\
\text { Residual }\end{array}$ & 75 & 1.04 & 0.01 & & \\
\hline Jumlah/Total & 76 & 28.45 & & & \\
\hline
\end{tabular}

\section{Validasi Model}

Pada tahapan selanjutnya setelah persamaan regresi terpilih yang akan diaplikasikan, perlu dilakukan validasi model. Validasi model dilakukan dengan menghitung nilai simpangan agregatif (Sa) dan simpangan rataan $(\mathrm{Sr})$ dari nilai volume aktual dan volume taksiran hasil persamaan regresi terpilih dan nilai standar error yang terbentuk. Hasil perhitungan nilai simpangan agregatif (Sa) adalah -1,86 dan simpangan rataan $(\mathrm{Sr})$ adalah 3,212.

Dari hasil tersebut di atas menunjukkan bahwa semua model persamaan regresi pendugaan volume terpilih dapat dilanjutkan penyusunan Tabel Volume Pohon. Penentuan kriteria ini berdasarkan standar menurut Spurr (1951) dan Husch (1963) yang menyatakan bahwa model pendugaan volume pohon yang baik adalah persamaan yang mempunyai nilai simpangan agregatif kurang dari $1 \%$ dan simpangan rataan kurang dari $10 \%$.

\section{KESIMPULAN DAN SARAN}

\section{A. Kesimpulan}

1. Berdasarkan hasil analisis hubungan diameter dan tinggi terdapat hubungan yang erat dari kedua variabel tersebut sehingga dapat disusun model pendugaan volume berdasarkan satu variabel saja (tariff).

2. Model persamaan hubungan diameter dan tinggi adalah :

$$
\mathrm{T}=11,473+0,2629 \mathrm{D}-0.001 \mathrm{D}^{2}
$$

3. Model persamaan terpilih berdasarkan niliai standard error, koefisien determinasi dan nilai F-hitung serta validasi model adalah :

$\log \mathrm{V}=-3,6751+2,4022 \log \mathrm{D}$

Atau

$\mathrm{V}=0,000211 \mathrm{D}^{2,4022}$

\section{B. Saran}

Penggunaan persamaan volume ini bersifat lokal artinya hanya pada daerah penelitian saja karena penggunaan secara umum akan memberikan hasil yang berbeda yang disebabkan oleh perbedaan site. 


\section{DAFTAR PUSTAKA}

Anonim, 1999. PT. Inhutani Labanan Menuju Pengelolaan Hutan Lestari (tidak diterbitkan)

Bustomi, S., Harbagung, D. Wahyono dan I.B.P. Parthama 1998. Petunjuk Teknis Tata Cara Penyusunan Tabel Volume Pohon. Badan Penelitian dan Pengembangan Kehutanan. Pusat Penelitian dan Pengembangan hutan Konservasi Alam. Info Hutan bogor.

Chapman, H.H and W.H Meyer 1949. Forest Mensuration. Mc. Graw Hill Book Company Inc. New York.

Husch, B. 1963. Forest Mensuration and Statistics. Ronald Press Company Inc. New York.

Loetsch, F \& Haller, K. 1973. Forest Inventory Volume II. BLV Verlagsgesellschaft, Munchen.

Martawijaya A, I. Kartasujana, K. Kadir, S.A. Prawira 1981. Atlas Kayu Indonesia jilid I. Balai Penelitian Hasil Hutan. Badan Penelitian dan pengembangan Pertanian. Bogor

Schmidt, F. H. \& J. H. A. Ferguson. 1951. Rainfall Type Based on Wet and Dry Period Ratios for Indonesia with Western New Guinea. Verhand 42. Direktorat Meteorologi dan Geofisika. Jakarta.

Sist, P and A. Saridan. 1998. Description of the Primary Low Land Forest of Berau. Silvicultural Research in a Low Land Mixed Dipterocarp Forest of East Kalimantan. Cirad Foret France.

Soemarna, K \& Suprapto. 1971. Tabel Volume Per Pohon Shorea spp., Vatica spp., Diptrocarpus spp., Hopea spp. dan Jenis Lain-lain di Kalimantan Tengah, Laporan LPH, No. 133.

Soerianegara, I and R.H.M.J Lemmens (Editors). 1994. Timber trees: Major commercial timber. Plant Resources of South - east Asia (PROSEA) No. 5 (1). Bogor.

Steel, R.G.D. \& H. Torrie. 1960. Principles and Procedures of Statistics. McGraw - Hill book Company, Inc.

Spurr, S.H. 1951. Forest Inventory. The Ronald Press Co. New York. 